\title{
Enhanced Coagulation deal with cryogenic micro-polluted groundwater
}

\author{
Ya shu Yuan ${ }^{1, a^{*}}$, Yan Zhang ${ }^{2, b}$, Hui yu Guo ${ }^{3, c}$, Zhen Fang ${ }^{4, c}$ \\ 1,2,3,4 Shenyang Jianzhu Univertisy,shenyang,liaoning,china \\ a*yuanyashu2007@163.com, ${ }^{\mathrm{b}} 1633268881 @ q q . c o m, 1^{\mathrm{c}}$ 3898806501@139.com, \\ d1101279412@qq.com
}

Keywords: groundwater; low temperature and turbidity; enhanced coagulation; Activated Carbon Abstract: Winter in northern China, the presence of low temperature and turbidity micro pollution of groundwater.a conventional water treatment process finished water can not reach drinking water standards, so the need for process improvement, enhanced coagulation using powdered activated carbon with a very good treatment effect. determined under the experimental conditions and PAC together powdered activated carbon dosing dealing with the best, PAC dosage of $10 \mathrm{mg} / \mathrm{L}$,powdered activated carbon dosing $20 \mathrm{mg} / \mathrm{L}$, this time on the removal rate of $59.6 \% \mathrm{Fe}$, Mn removal rate was $40.9 \%$, turbidity removal rate was $60.6 \%$ and $U_{2} 254$ removal rate was $75.2 \%$.

\section{Introduction}

Winter in northern China ,Groundwater has the following characteristics :low temperature and turbidity ,high levels of $\mathrm{Fe}, \mathrm{Mn}, \mathrm{NH}_{4}{ }^{+}-\mathrm{N}$ and $\mathrm{UV}_{254}$ content. Conventional approach is that by increasing the dosage of coagulant to reduce pollutants in the water, but the coagulant dosing the amount of the increase, not only increased costs, will result in increased sludge, filter filtration cycle is short and other issues ${ }^{[1]}$; pre-oxidized chlorine, It generates byproducts such as halomethanes with organics in water, such deputy the product must strictly control their content in water ${ }^{[2]}$. So urgently seeking an economical processing temperature slightly contaminated groundwater manner [3-4].

Enhanced Coagulation can not only remove Fe,Mn and the removal of $\mathrm{UV}_{254}$ also have a good effect, enhanced coagulation have dosing potassium permanganate, powdered activated carbon and other methods ${ }^{[5]}$. The use of potassium permanganate have strengthened the role of turbidity, for the removal of organic also has some effect, But potassium permanganate pre-oxidation can increase the concentration of $\mathrm{Mn}$ in water, increasing the burden on the subsequent treatment; The water temperature is not easy to destabilization of colloidal particles, greatly reduced the probability of collision, particles easily flocculation ${ }^{[6]}$, Powdered activated carbon on the one hand can play the role of adsorb pollutants, on the other hand can increase the raw water turbidity of the water flocculation play very good results for subsequent processing burden.In this study, powder activated carbon as enhanced coagulation agents.

\section{Experimental water quality and methods}

Experimental Water.Experimental water use the manner of lab water distribution to analog source water situation of Hailar waterworks, the specific indicators in Table 1. 
Tab.1 Basic indicators of water quality conditions

\begin{tabular}{lllllll}
\hline index & $\begin{array}{l}\mathrm{Fe} \\
(\mathrm{mg} / \mathrm{L})\end{array}$ & $\begin{array}{l}\mathrm{Mn} \\
(\mathrm{mg} / \mathrm{L})\end{array}$ & $\begin{array}{l}\mathrm{NH}_{4}{ }^{+}-\mathrm{N} \\
(\mathrm{mg} / \mathrm{L})\end{array}$ & $\mathrm{UV}_{254}$ & $\mathrm{NTU}$ & $\mathrm{T} /\left({ }^{\circ} \mathrm{C}\right)$ \\
\hline limit & 4.23 & 1.1 & 1.29 & 0.26 & 1.75 & 4
\end{tabular}

Experimental Methods.Use Six joint mixer simulation coagulation. Coagulation agent used is PAC, after the stirrer speed and stability, adding PAC to $250 \mathrm{r} / \mathrm{min}$ stirring $30 \mathrm{~s} \sim 60 \mathrm{~s}$, adjust the speed of $80 \sim 100 \mathrm{r} /$ min to maintain 5min, and then adjust the speed to $40 \sim 60 \mathrm{r} / \mathrm{min}$ to maintain $10 \mathrm{~min}$, After precipitation 20min, the supernatant is tested for residual turbidity, $\mathrm{UV}_{254}, \mathrm{Fe}, \mathrm{Mn}$ and other indicators.

\section{Enhanced Coagulation experiment}

Enhanced Coagulation is added powdered activated carbon during Coagulation to achieve enhanced coagulation effect,the experiment of powdered activated carbon dosing in three ways: A method, in front of PAC dosing of powdered activated carbon 5 minutes; B method, powdered activated carbon and PAC simultaneously dosing, C method, powdered activated carbon dosing after PAC 2 minutes. By detecting water quality, to determine the best dosage of powdered activated carbon and dosing time . PAC dosing experiments in an amount of 10mg / L (pre-testing to determine the optimal dose), Water quality tests are shown in Table 1. Experiment on three species of activated carbon dosing method, dosage of activated carbon is determined $0 \sim 40 \mathrm{mg} / \mathrm{L}$ range.

powdered activated carbon for removal of Fe.Powdered activated carbon treatment effect of Fe in Figure 1.

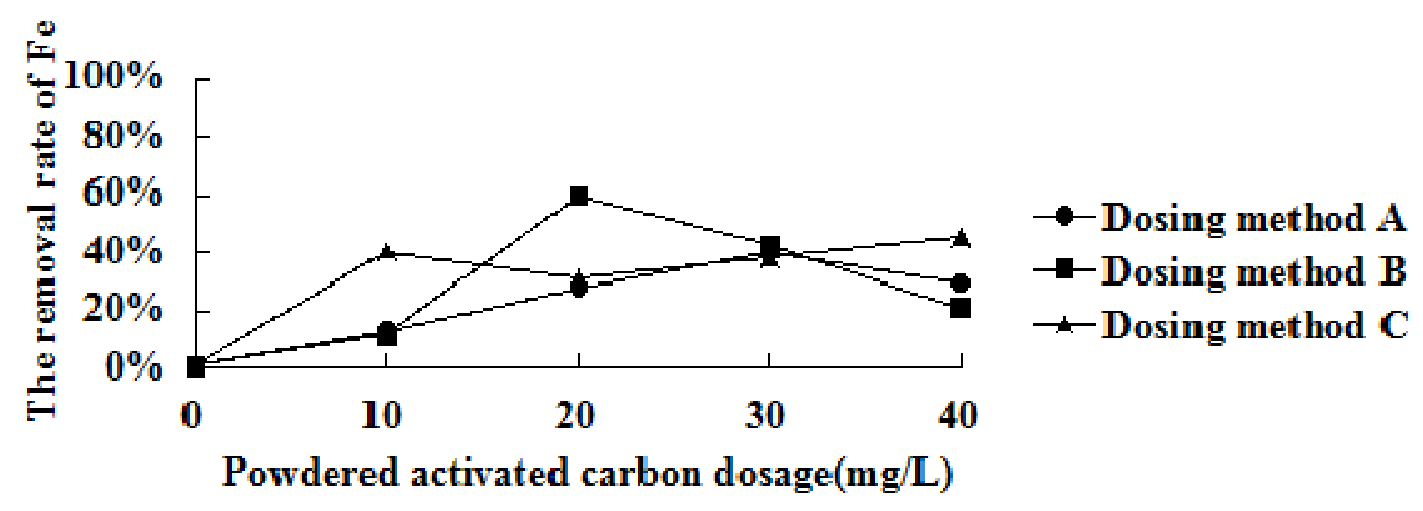

Fig.1 Effect of powdered activated carbon dosage of removal of Fe

As can be seen from Figure 1, without adding powdered activated carbon the removal rate of Fe is $1 \%$, After dosing of powdered activated carbon in A, B, C three methods of Fe removal have some effect, because powdered activated carbon have characteristics of adsorbent and catalyst, In post-dosing of powdered activated carbon Fe,Mn and other metal ions can be oxidized, which translates into higher valence state and form a precipitate, Powdered activated carbon Adsorb resulting precipitate, so that the decrease of $\mathrm{Fe}$ and $\mathrm{Mn}$ in water.A dosing method in dosage $30 \mathrm{mg} / \mathrm{L}$ of powdered activated carbon, Fe has the highest removal rate, which was $40.2 \%$; $\mathrm{B}$ dosing method in dosage $20 \mathrm{mg}$ / $\mathrm{L}$ of powdered activated carbon, Fe has the highest removal rate, which was $59.6 \%$; $\mathrm{C}$ dosing method in dosage 
$10 \mathrm{mg}$ / $\mathrm{L}$ of powdered activated carbon, Fe has the highest removal rate,which was $45.2 \%$.according to shown at Figure 1, to make Fe removal rate is best should choose B mode dosage $20 \mathrm{mg} / \mathrm{L}$ of powdered activated carbon, the removal rate can reach $59.6 \%$.

powdered activated carbon for the removal of Mn.Powder activated carbon for removal of $\mathrm{Mn}$ in Figure 2.

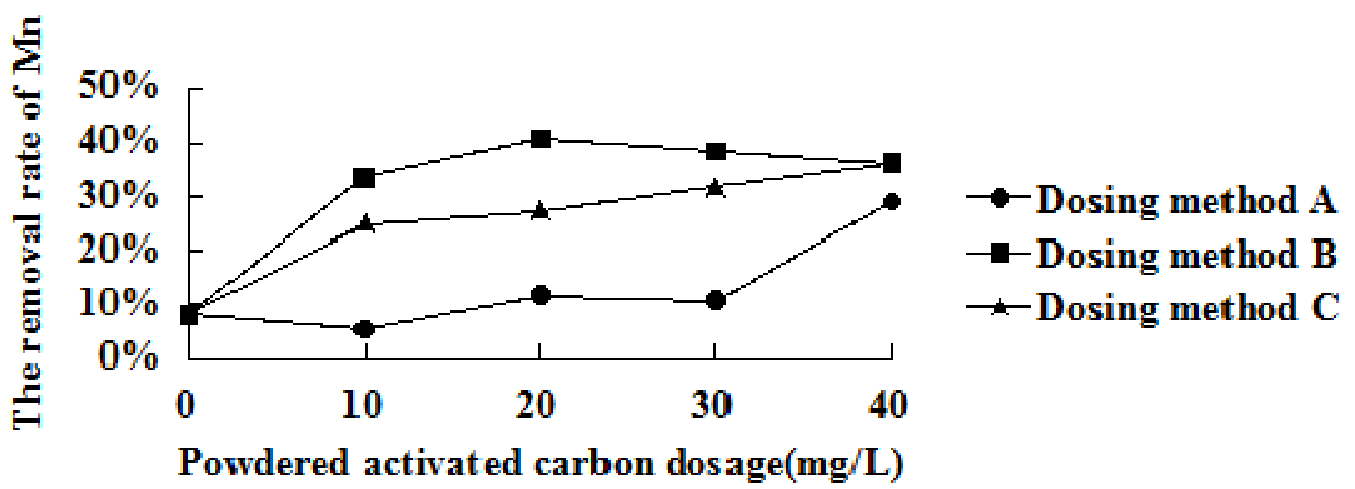

Fig.2 Effect of powdered activated carbon dosage of removal of Mn

As can be seen from Figure 2, without adding activated carbon, PAC coagulation can remove $8.3 \%$ of $\mathrm{Mn}$, after adding powdered activated carbon have a certain effect, The reason why Powdered Activated carbon can make Mn removal rate elevated same as $\mathrm{Fe}$. This is because the catalytic properties and adsorption properties of activated carbon powder.A dosing method when adding 40mg / L of powdered activated carbon, The removal rate of Mn was highest and at this time was $29.1 \%$; B dosing method in dosage 20mg / L of powdered activated carbon ,Mn removal rate was highest, at this time up to $40.9 \%$; mode $\mathrm{C}$ when adding $40 \mathrm{mg} / \mathrm{L}$ of powdered activated carbon, Mn removal rate was highest, at this time was $36.1 \%$ according to figure. 2, B mode in dosage $20 \mathrm{mg} / \mathrm{L}$ of powdered activated carbon when Mn removal was best, the removal rate can reach to $40.9 \%$.

powdered activated carbon for removal of turbidity.Powdered activated carbon for the removal of turbidity in Figure 3.

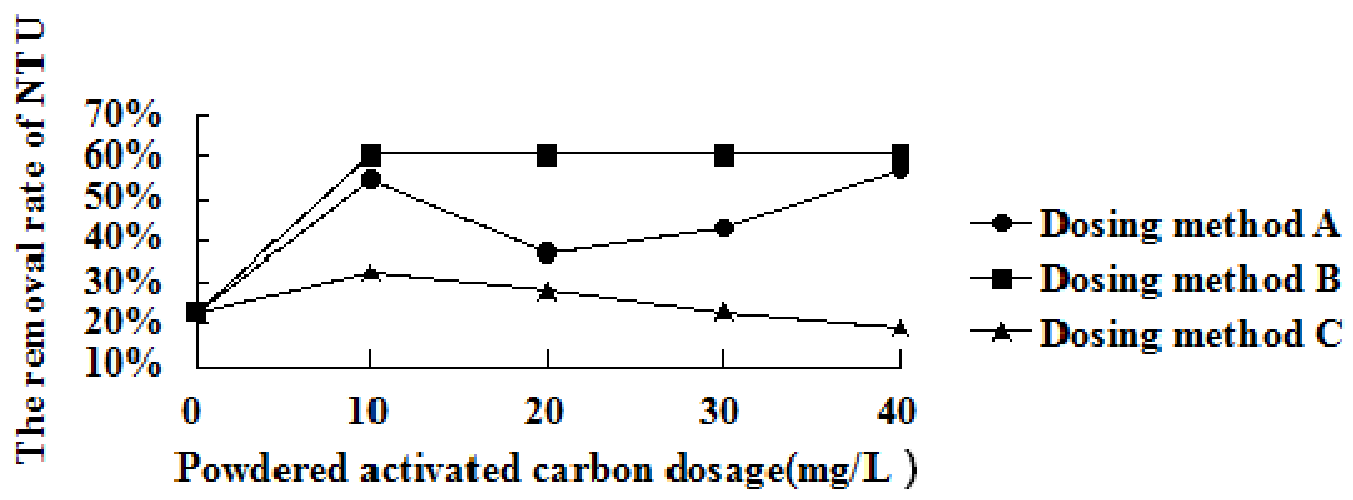

Fig.3 Effect of powdered activated carbon dosage of removal of turbidity 
As can be seen from Figure 3 without adding activated carbon, PAC coagulation can go out $22.9 \%$ of turbidity. after adding the powdered activated carbon A mode and B mode have a certain effect .A dosing method in dosage $40 \mathrm{mg} / \mathrm{L}$ of powder activated carbon the turbidity removal rate was highest, which was $57.1 \%$.B dosing method in dosage greater than $10 \mathrm{mg} / \mathrm{L}$ of powdered activated carbon when turbidity stabilized, then turbidity removal rate was $60.6 \%$; the way $\mathrm{C}$ turbidity removal rate was highest when powdered activated carbon dosage $10 \mathrm{mg} / \mathrm{L}$, which was $32.6 \%$, continue dosing turbidity but declined .C way turbidity removal rate bad because of after added coagulant dosing of powdered activated carbon, then the coagulant has a certain floc, coagulant concentration in the solution are already low, and will not continue to capture dosing of powdered activated carbon, the dosing of powdered activated carbon will cause increased turbidity, $\mathrm{C}$ and $\mathrm{A}$ and $\mathrm{B}$ of different removal efficiency. In summary, to make higher turbidity removal rate should choose B mode in dosing 10mg / L of powdered activated carbon, when turbidity removal rate was $60.6 \%$.

powdered activated carbon for removal of $\mathbf{U V}_{254}$. Powdered activated carbon for removal of $\mathrm{UV}_{254}$ as shown in Figure 4.

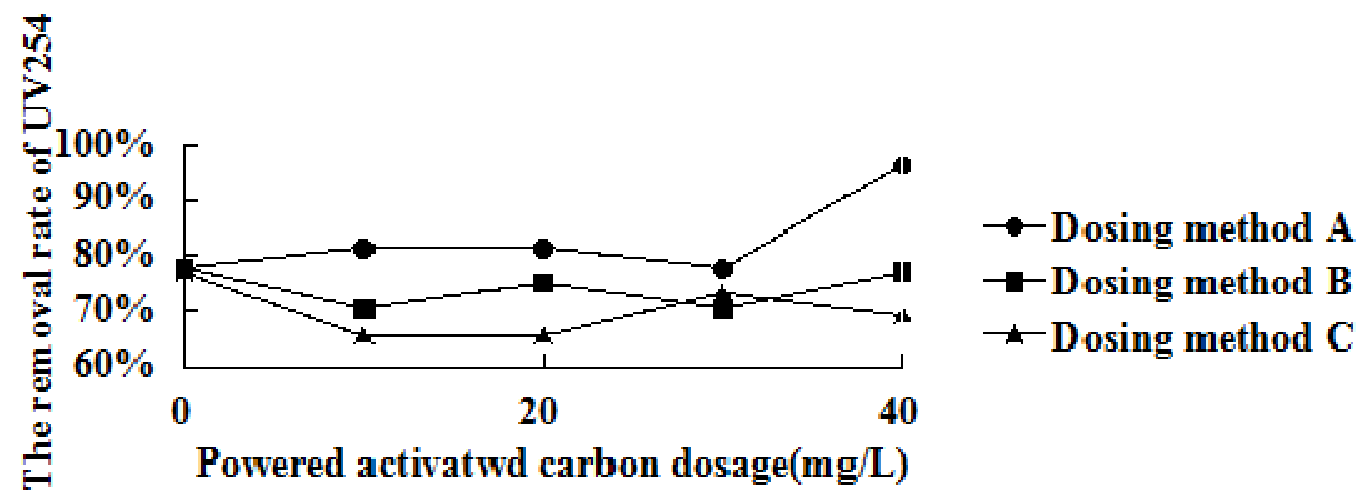

Fig.4 Effect of powdered activated carbon dosage of removal of $\mathrm{UV}_{254}$

Powdered activated carbon for the removal of $\mathrm{UV}_{254}$ little effect, $\mathrm{B}$ and $\mathrm{C}$ were two ways for removal UV254 than just adding PAC poor, A way of adding powdered activated carbon to remove $\mathrm{UV}_{254}$ Was better than just dosing PAC, it is because Only a small amount of easily removed organic can be Adsorbed by powdered activated carbon, removal of organic matter mainly by coagulation, and A way before coagulation adding powdered activated carbon increased water turbidity can increase the coagulation effect, and organic removal rate will improve, so A way removed $\mathrm{UV}_{254}$ was better than the other methods. only adding $\mathrm{PAC}, \mathrm{UV}_{254}$ removal rate was $77.8 \%$;A way was the best way to remove $\mathrm{UV}_{254}$ when powdered activated carbon dosage of $40 \mathrm{mg}$ / L, $\mathrm{UV}_{254}$ removal rate was $96.3 \%$. B dosing method of powdered activated carbon dosage of $20 \mathrm{mg}$ / L when $\mathrm{UV}_{254}$ removal rate was $75.2 \%$.

\section{Conclusions}

Powdered Activated Carbon enhanced coagulation process of Low temperature and slightly contaminated groundwater has good removal effect, which powdered activated carbon dosing in conjunction with PAC, PAC dosage of $10 \mathrm{mg} / \mathrm{L}$ and powdered activated carbon dosage of 20mg / $\mathrm{L}$ worked best, at this time in addition to poor $\mathrm{UV}_{254}$ removal effect, $\mathrm{Fe}, \mathrm{Mn}$, turbidity are better. 
processing the best Fe removal was $59.6 \%$, Mn removal rate was $40.9 \%$, the removal of turbidity was $60.6 \%, \mathrm{UV}_{254}$ removal rate was $75.2 \%$.

If you want the best $\mathrm{UV}_{254}$ removal rate should choose before the PAC powdered activated carbon dosing manner, the dosage of $40 \mathrm{mg} / \mathrm{L}, \mathrm{UV}_{254}$ removal rate was $96.3 \%$. In this case the $\mathrm{Fe}$ removal rate was $29.6 \%$, the Mn removal rate was $29.1 \%$, turbidity removal rate was $57.1 \%$.

A, B, C was three ways for $\mathrm{NH}_{4}{ }^{+}-\mathrm{N}$ removal is not obvious.

powdered activated carbon is cheap and adsorption fast, do not require large-scale transformation of the old water plant at the waterworks enhanced coagulation, as long as the water combined with the original simple transformation can be achieved, the existing plants in response to effective measures to source water quality deterioration and water pollution when water burst and can save processing costs.

\section{References}

[1] Li dong ZHANG, Yan wen LI. Comparative Study of Application of coagulants and coagulant treatment low temperature and low turbidity water [J]. Jilin Institute of Chemical Technology, 2012,31(11):35-37,56.

[2]Yuan xin GE, Zhi liang ZHU, et.al. Analysis and assessment of health risk on disinfection of drinking Water[J]. Water Purification Technology, 25(3):1-5.

[3]Yu hua ZHAO, Yan LI, et.al. Effect of Grounder Water Containing Iron and Manganese with Ammonium and Organics Pollutants on the Contact Oxidation Filter Treatment [J]. Journal of Shenyang Jianzhu University (Natural Science), 2011,27(4):746-750.

[4]Yu hua ZHAO, Xu YAN, et.al. Study on Purification Efficiency of Three-Level Filtration for Treating The Composite Micro-Polluted Groundwater [J]. Journal of Shenyang Jianzhu University (Natural Science), 2014,30(4): 536-541.

[5]Hui LIU ,Xing LI. Experimental study on the treatment of low temperature and low turbidity water with Enhanced coagulation[D].Harbin Engineering University,2012.

[6]Hai ying LI. On low temperature and low turbidity water treatment technology [J]. Environmental Science Survey, 2009, 28 (Suppl) : 84- 86. 